\title{
Building Entrepreneurial Teamwork Competencies In Collaborative Learning Via Peer Assessments
}

Peter H. Hackbert, (E-mail: phackbert@sierranevada.edu), Sierra Nevada College

\begin{abstract}
Entrepreneurship courses commonly use various kinds of group work, cooperative learning, study circles and study teams. A major challenge of this pedagogy is the unbiased grading of group members based on the accountability of individual performances. This paper provides an approach to using student peer assessment to provide feedback on individual performances within an entrepreneurial team project so that grades may be assigned in an equitable manner within entrepreneurship education.
\end{abstract}

\section{Introduction}

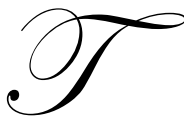

here is little doubt that the founder team, or the top management team is a key component in the success for failure of the new venture (Virany and Tushman, 1986). The new venture team is crucial to attracting investors, for investors look for experience and integrity in management (Tyebjee and Bruno, 1984). The team is also a key element in venture growth (Bird, 1989), and without a team to plan, manage and control the activities of the growing enterprise, the firm's growth will be limited to what the founder can personally supervise and manage (McCarthy, Krueger, and Schoenecker, 1990).

A gap exists in the entrepreneurial literature particularly as it relates to teaching students the value derived from entrepreneurial teamwork. Knowledge of teamwork competence and group dynamics issues may help determine the venture's performance (Kamm, Schuman, Seeger and Nurick, 1990) and is one major responsibility of the founding entrepreneur (Katzenbach and Smith, 1993). A well-developed team can bring the benefits of team decision-making, diversity, breadth of knowledge, acceptance of decisions, and legitimacy about a venture's potential viability for market acceptance (Michaelson, Watson, and Black, 1989).

For the purposes of this paper an entrepreneurial team is defined as several individuals coming together to create value in a product or service for a period of 15 weeks. These teams may be working on behave of a outside client or as a group convened to develop a specific class project. Undergraduate learners when placed in teams can learn best when they are actively involved in the process. Researchers report that, regardless of the subject matter, learners working in small groups tend to learn more of what is taught and retain it longer than when the same content is presented in other instructional formats. Learners who work in collaborative groups also appear more satisfied with their classes. (Sources: Beckman, 1990; Chickering and Gamson, 1991; Collier, 1980; Cooper and Associates, 1990; Goodsell, Maher, Tinto, and Associates, 1992; Johnson and Johnson, 1989; Johnson, Johnson, and Smith, 1991; Kohn, 1986; McKeachie, Pintrich, Lin and Smith, 1986; Slavin, 1980, 1983; Whitman, 1988) Various names have been given to this form of instruction, and there are some distinctions among these: learning communities, collaborative learning, collective learning, cooperative learning, peer learning, peer teaching, reciprocal learning, team learning, study circles, study groups, and work groups. But all in all, there are three general types of group work: informal learning groups, formal learning groups, and study teams.

Informal learning groups are ad hoc temporary clustering of learners within a single class session. Informal learning groups can be initiated, for example, by asking learners to turn to a neighbor and spend two minutes discussing a question the instructor has posed. Instructors can also form groups of three to five to solve a problem or 
pose a question. Informal groups are organized at any time in a class of any size to check on learners' understanding of the material, to give learners an opportunity to apply what they are learning, or to provide a change of pace.

Formal learning groups are teams established to complete a specific task such as perform a lab experiment, write a report, carry out a project, or prepare a position paper. These groups may complete their work in a single class session or over several weeks. Typically, learners work together until the task is finished, and their project is graded.

Study teams, study circles and tutorial study groups are long-term groups (usually existing over the course of a semester) with stable membership whose primary responsibility is to provide member support, encouragement, and assistance in completing the course requirements and assignments. Study teams also inform their members about lectures and assignments when someone has missed a session. The larger the class and the more complex the subject matter, the more valuable study teams can be.

Group-based learning projects are used in many small business management and entrepreneurship education courses, and collaborative learning activities can increase learners' understanding and teamwork competence. The value of small groups to facilitate learning was first noted in Western Civilization in ancient Greece, replicated in the tutorial concept at Oxford and Cambridge Universities, and most recently documented by faculty at International Management Center at Buckingham (IMCB) in the United Kingdom (Prideaux and Ford, 1988a, 1988b). Teams facilitate structural and communicational devices that empower potential entrepreneurial to seize opportunities for innovation (Brazeal and Herbert, 1999). Many professors now view group-based class project efforts as important to learning exercises and training opportunities for their learners (Beatty, 1992; Chronicle of Higher Education 1989; Henke Jr.; et.al. 1988). Previous research in this area points to conclusive agreement as to the value of group-based projects in small business management and entrepreneurship classes. Among the many advantages offered by group projects, learners acquire real-world experience, translate conceptual material into practice, and work with peers. Many learners appear to prefer group-based projects to individual assignments (Cooper and Associates, 1990). For instructors, the major advantages are similar to those enjoyed by the learners. Group projects provide learners with opportunities to bridge the gap between theory and practice in a semistructured academic environment.

Group-based learning may be used in many types of learning experiences in small business management and entrepreneurship classes. These include group case presentations and analysis, such as class projects in developing business or marketing plans, role playing scenarios, computer games and simulation, and presentations of assigned articles or readings. Group learning experiences have been and are being used in developing and reviewing business plans, marketing research, personal selling, sales marketing, advertising, consumer research, and capstone classes. Regardless of the application, all these group efforts involve a common component - - the overall effort of the group is determined by how well or poorly these learners work together on a single assignment. As elusive as it may be, insight into a group's interaction is necessary of the instructor in order to achieve equitable grading. This paper focuses on the issue of evaluating individual contributions and proposes an approach, based on assessment by peers, to better understand how individual group members perform within the group.

\section{KEYS TO UNDERSTANDING GROUP BEHAVIOR AND GROUP DYNAMICS}

All teams are groups, but not all groups are teams. Teams are a specialized kind of group. Teams are defined as two or more people with a "specific performance objective or recognizable goal to be attained; and coordination of activity among the members of the team are required for the attainment of the team goal or objective" (Dollinger, 1999). A group is defined as a collection of people who interact and share a common goal or purpose. The common attribute or purpose constitutes the goal of the group. The distinction between a group and a team, while not always clear, appears to have much to do with the emphasis given within teams, to completing a task and fulfilling a performance objective that takes collaboration over a period of time. For the group to function there must also be cohesion to hold members together. Group cohesion relates to the degree to which members believe they share common attributes. In addition, there are typically informal group norms or informal rules about how members are expected to behave. Members of a group expect certain types of behavior from the fellow members 
and may view other behaviors as unacceptable. Groups used in small business management and entrepreneurial classes typically meet these social psychological requirements, thus permitting the use of many of the research findings of social psychologists to better understand how groups in classes function and perform.

Social psychologists have observed a number of group phenomena that may be important to the instructor who uses groups in classes. One consistent research finding is that people working in groups generate more ideas. Not only do people bring different ideas to the groups; something about the exchange of ideas in groups generates even more ideas. The level of "ideation" is 60 to 80 percent higher in groups than for individuals (Lorge, 1958). Those who study groups note that communication seems to involve two levels, often simultaneously, one that has been come to be called "task," the other "process." The task is the activity the group expects to perform. When learners participate in groups, they bring with them their individual needs for identity, recognition, inclusion, status, and understanding. To put the matter bluntly, learners bring their egos to the team, and those egos need to be fed, supported, nurtured, and soothed. Sometimes this requires "time out" from the task to deal with the personal concerns of one of the members, but more often the process work of the group is intermingled with its work on the task. It is natural, therefore, that the group is not always "on task," because sometimes the group needs to communicate, laugh, empathize, or just play.

Another such phenomenon is the free rider effect. The free rider is a person who benefits from the group but who gives little in return. The free rider does not participate fully, and contributes little or none of the work. This person makes a conscious decision to let others in the group do most of the work and then "rides through" on the group grade. The free rider constitutes one major problem in using groups in classroom activities. Because they know their efforts are not individually monitored and rewarded, individual members may see more reward per unit of effort in "slacking off" when the group's rewards are divided equally among the group, regardless of how much each contributes. If group performances are to be successful, instructors must strive to eliminate the opportunities for free riding.

A third phenomenon sometimes experienced by groups is when group members are apathetic or don't do their share of the group-based tasks. Apathy usually develops when members are not excited about the project. Sometimes apathy also occurs when the group has not fostered a climate for risk-taking. What may be mistaken for apathy is really a reluctance to participate because it is not clear how the contribution will be received. Usually, apathy - - real apathy or other behavior masquerading as apathy - - can be overcome if it is identified and discussed.

More troublesome than apathy is social loafing. Social loafing is defined as a tendency for some people to exert less effort when they pool their efforts toward a common goal than when they are held individually accountable. Research has shown that individuals in general tend not to work as hard in groups as they do as individuals. Known as the "Ringleman Effect" from the researcher by that name who conducted crude tug-of-war experiments in the 1880 's, it has been established that two people don't pull twice as hard as one, and so forth, as group size increases. Social psychologists studies have more recent established clearly a similar idea called "social loafing." Most social loafing occurs when it is not possible to distinguish the individual's contribution to the group output (Pavitt and Curtis, 1990). Because there may be a number of reasons for social loafing, it is often more complex than free riding. For example, a social loafer may feel intimated by others in the group and therefore contribute less. Very introverted learners and those with language or cultural differences may be other examples. Whatever the reason, social loafers contribute less effort to the group than they applied when working individually. Social loafing is a serious problem that occurs frequently in learner groups when some team members diminish other team member's efforts. As with free riding, instructors should strive to reduce or eliminate opportunities for social loafing.

The last important occurrence involves group leadership. This is the process by which certain individuals motivate and guide the group. Sometimes leaders are appointed, others times their role evolves as the group begins to function. Group leaders also fall into different categories. For example, task leaders excel at organizing work, setting standards, and focusing on attainment of goals. Social leaders are able to build teamwork among members, mediate conflict, and provide support for other members. Some leaders are charismatic members with the compelling vision of a desired state of affairs, the ability to communicate outcomes in clear and simple language to 
their peers, and enough optimism and faith in the group to inspire the others to follow. Since such leaders are often very positive influences in a group. It makes sense for instructors to identify leadership attributes and reward them for their performance.

For the entrepreneurship and small business education instructor, awareness of the serious patterns of group behavior is important because they do occur, at least to some extent, in almost all entrepreneurship classroom projects. Internal levels of cohesiveness and norms will vary from group to group. In addition to the nominal group leader, learner groups may also include social loafers, free riders, task leaders, social leaders, charismatic leaders, and those who do their share but little more. Many social psychologists believe that individual accountability plays a major role in increasing learner performance in groups and in discouraging social loafers and free riders. A mechanism is needed for the small business management and entrepreneurial instructor to better identify individual behaviors and performance within a group.

\section{PROBLEMS IN GRADING ENTREPRENEURIAL TEAM PERFORMANCES}

Team member performances are inherently difficult to grade, with a major problem being the assignment of grades to individual members. Learner groups often involve a number of members whose contribution is inconsistent with the overall group effort. Some may assume leadership roles and contribute much more than might be expected, while others are content to contribute much less. Some become social loafers or free riders. Still others contribute about what the group expects of them, but little more. These behaviors may result because members have different objectives or expectations. Some learners may become very interested in the group effort and very committed to the project, while others may be interested only in the grades they hope to receive. This diversity of objectives and expectations is a major concern; both instructors and learners desire realistic assessment, fair grading, and equitable assignments of grades to group members (Justice and Marineau, 1988). Previous research suggests that perceptions of work inequality translate into perceptions of grade inequality and into overall perceptions of unfairness in grading.

\section{DIFFICULTY IN ASSESSING INDIVIDUAL EFFORTS IN ENTREPRENEURIAL TEAMS}

A number of factors contribute to the difficulty of grading team efforts. There is often an inequality in quantity and quality work performed by the individual team members. Some learners excel in groups, while others falter badly. Some members are more enlightened and talented and contribute a high quality of work, while others may be incapable of producing at that level. Learners also vary in the degree of their effort and commitment, which results in uneven performances within a group. Interpersonal conflicts among members also affect behavior. Some members may be intimidated by others and thus perform at a lower level, while other members may not be capable of working together in an amiable manner. The group's high performers may become resentful of low performers, especially if the low performers receive comparable grades.

Because of the potential for uneven performances within teams, evaluating entrepreneurial teamwork performance is often difficult. Many researchers believe that the problem of inequitable contributions can be solved with a grading system that gives appropriate weight to both individual contributions and the group's collective achievements. A method is needed that rewards learners for equitable work in project groups, one that recognizes that individual objectives, abilities, motivations, and contributions vary. This paper suggests an approach using peer assessment that permits an instructor to more equitably evaluate and grade individual performances within the team.

\section{SELECTION PEER RATING CRITERIA}

Teams begin to function effectively only when they first have fully grasped the reality of how they function, particularly when individuals in the group recognize that they are working in situations that are dissonant or uncomfortable (Goldman, 2002). Appropriate assessment criteria must be established before using peer assessment as a method to better determine individual efforts within a group. These criteria should involve factors seen as expected by both instructors and learners in determining individual contributions to a group. Of course, all instructors and learners do not universally accept a single set of criteria. The author has developed a process for 
learner assessment in classroom group projects that is based on different expectations of behavior found to be important and meaningful in small business management and entrepreneurship classroom group projects. Learners expect certain types of behavior from their group peers: these become group norms. Based on a number of actual group classroom experiences, the following issues appear to be representative of these expectations.

\section{DEPENDABILITY AND APPRECIATION}

Experiences have shown that group project success is sensitive to the appreciation of members and their diligence attending meetings carrying out tasks. This process measures dependability and availability using three dimensions: (1) attendance at meetings, (2) appreciation of team members, and (3) dependability. The dimensions are used to address such comments as " He was never there" or "she showed appreciation to other members when they completed work task" and "he just could not be depended upon to complete his task on time." In learner groups, members expect their teammates to come to meetings, be available, and be dependable, just as professional team members do.

\section{CONTRIBUTION AND WORK QUALITY}

Conceptual contribution and work output are also important to group success. This process measures contribution and work quality from two dimensions: (1) quality of ideas, and (2) quality of work standards. These dimensions address such learner concerns as "He was there but he didn't contribute much" or " Her work was so poor, we always had to redo it." Typically, most group members expect high-quality ideas and work from their peers to ensure their success as a group.

\section{PEER GROUP EQUITY AND INTERACTION}

Dimensions of work group equity of performance and work/study, or personal interactive styles of members are also important to group success or failure. Peer group equity and interaction are measured by three factors: (1) facilitating team achievement (2) completing a fair share of the work, and (3) being easy to work with. These address such concerns as "He is really smart, but was a real pain to deal with" or "she never really understood what was needed to be done and cost us precious time." Experience has shown that learners in groups expect fellow group members to help achieve group's goal, and to be accommodating and easy to get along with.

\section{OVERALL ASSESSMENT}

One final assessment dimension of team member contribution is obtained through a summary statement assessing each group member at the completion of the project. This dimension provides an overall measure of individual performance.

\section{THE INSTRUMENT}

Using these dimensions, criteria for an instrument were developed and refined over a number of classroom applications within five semesters. A teamwork abilities indicator was administered to team members via an anonymous online survey. This practice and these criteria permit group members to become familiar with how to evaluate individual performances based on what was perceived as reasonable expectations of team member behavior. The premise is the team members are in the best position to judge performance of their peers in such an assessment.

Exhibit 1 illustrates the final version of the instrument. Nine peer-reading criteria used semantic differential items scored on a range of seven points, from 7 , the highest possible rating to 1 , the lowest possible rating. At the beginning sessions of the course, learners are introduced to the online surveys which presented attributes of high-performing teams. Each student was asked to rate the level of importance of entrepreneurial attributes, and teamwork competencies on an anonymous online survey (Hackbert, 2000a, 2000b) and told how it will be used to help judge performances within groups. At the mid-term and again upon the completion of a cross- 
functional class project, group members are asked to rate themselves on the items. Each member is then asked to rate every other member on the same items. In this way, there is the peer rating on each of the items for each of a group's members. Learners are also encouraged to write comments relevant to their ratings on the back of the instrument. Exhibit 2 illustrates how learners summarize the E-team meeting times, for each session and the total Eteam time-on-task for the course.

\section{Exhibit 1: Peer- And Self-Assessment Instrument}

Group Member Being Rated:

Learner Name:

Instructions:

You are to complete a rating sheet for yourself and all other members of your team. All team members must be rated.

All rating sheets will be kept confidential. No team member will see the rating sheets. They will be used only by the course instructor to help determine individual team member's contributions to the overall team performance.

\begin{tabular}{|c|c|c|c|c|c|c|c|c|c|}
\hline \multicolumn{10}{|c|}{ Please rate each team member on the following: } \\
\hline & & 7 & 6 & 5 & 4 & 3 & 2 & 1 & \\
\hline 1 & Always Shows Appreciation & - & - & - & - & - & - & - & Never Shows Appreciation \\
\hline 2 & Available When Needed & - & - & - & - & - & - & - & Unavailable When Needed \\
\hline 3 & High Standards & - & - & - & -_ & - & - & - & Low Standards \\
\hline 4 & Dependable, Trustworthy & - & - & - & _- & - & - & - & Undependable, Untrustable \\
\hline 5 & Promotes Shared Goals & - & - & $\ldots$ & _- & - & $\ldots$ & - & Low Commitment to Team \\
\hline 6 & Facilitated Goal Achievement & - & - & - & - & - & - & - & Hindered Goal Achievement \\
\hline 7 & $\begin{array}{l}\text { Allows Group to Take } \\
\text { Responsibility for Tasks }\end{array}$ & - & - & - & - & - & - & - & $\begin{array}{l}\text { Assumes Personal Respons-ibility } \\
\text { for Team Task }\end{array}$ \\
\hline 8 & $\begin{array}{l}\text { Communicates Need for } \\
\text { Cooperation }\end{array}$ & - & - & - & - & - & - & - & $\begin{array}{l}\text { Does not Communicate the Need } \\
\text { for Cooperation }\end{array}$ \\
\hline 9 & Overall Assessment High & - & - & - & $\ldots$ & - & - & - & Overall Assessment Low \\
\hline
\end{tabular}

The mean peer ratings are then compared to the self-ratings. The purpose of the comparison is to provide the instructor with insight into the performance of individual group members as seen by them and by their peers. There is little difficulty in administering this instrument to learners in a group. The instrument is easy to understand, and group members find it relatively simple to rate performance of each member of the group, including him or her. They also appreciate that the instrument is used to reward outstanding performances and to penalize unacceptable performances.

In most cases, group members accept the process as part of the course requirements and it runs smoothly. Some instructors, however, may believe that the process could be even smoother if team-building or training sessions were implemented within each group. These sessions could be undertaken when group members are introduced to the instrument at the beginning of the course and could involve clear expectations of what will be expected of them. This might reduce free riding and social loafing.

\section{Testing the Peer Rating Criteria}

To test these criteria, data were collected over several semesters' classes that had used the instruments. The total of toward 186 peer assessments provided the basis of the study.

To assess the relative importance of each factor rating on a member's overall assessment, multiple regression analysis was conducted using a member's overall assessments as the dependent variable. The other eight items were used as the dependent variable in a stepwise regression model. Only ratings of group members other 
than the learner rater were involved in the analysis. The overall model is highly significant with an $\mathrm{R} 2=.888$ and a corresponding $\mathrm{F}(7.206)=233.2 \mathrm{p}<.01$. This indicates a very strong relationship between the set of individual criteria ratings in the overall assessment of team members, which, in turn, suggests that the eight dimensions are useful measures of performance in learner groups.

Table 1: Significant Regression Variables Ranked In Order Of Importance

\begin{tabular}{llcccc}
\hline Rank & \multicolumn{1}{c}{ Variable } & $\begin{array}{c}\text { Raw } \\
\text { Weight }\end{array}$ & $\begin{array}{c}\text { Standardized } \\
\text { Weight }\end{array}$ & $\boldsymbol{T}$ & $\boldsymbol{P}$ \\
\hline 1 & Facilitated Goal Attainment & 0.183 & 0.210 & 4.60 & 0.000 \\
\hline 2 & Contributed High Quality Ideas & 0.177 & 0.200 & 4.31 & 0.000 \\
\hline 3 & Always Shows Appreciation & 0.182 & 0.156 & 4.00 & 0.000 \\
\hline 4 & Promotes Shared Goals & 0.138 & 0.155 & 4.96 & 0.000 \\
\hline 5 & Allows Group to Take Responsibility for Tasks & 0.138 & 0.154 & 3.33 & 0.001 \\
\hline 6 & Dependable, Trustworthy & 0.122 & 0.128 & 2.72 & 0.010 \\
\hline 7 & Communicated Need to Cooperation/ Teamwork & 0.114 & 0.128 & 2.40 & 0.017 \\
\hline 8 & Attendance at Meetings & 0.048 & 0.191 & 1.34 & 0.181 \\
\hline
\end{tabular}

Table 1 shows the results of stepwise procedure. All but one of the eight independent variables (attendance at meetings) entered the model. The failure of this dimension to enter the model is not surprising given that students use online web-learning in the courses. A possible explanation is that, due to collinearity, little is explained uniquely by this dimension, which thus yields little explanatory power. The table strongly suggests that the set of rating dimensions is highly related to an individual member's overall contribution to the team, as perceived by the team.

\section{Comparing Individual Team Member Performances}

To illustrate how the instruments may be used to help evaluate individual member's performance, a typical project team in a capstone business plan develop or senior-level management/entrepreneurship class is selected for analysis. Because of class size and the nature of the team project undertaken, this group contained six members. Table 2 compares each member's self-rating with the mean rating of her or his work on each in the nine items.

It is important to realize that the mean peer rating excludes the member's self-rating and are thus representative of member's peers. The Wilcoxon signed-rank-sum test for paired samples was used to test differences between the self-and peer ratings for each of the six group members. Table 2 also shows the significance of these tests. The discussions that followed were based on the analysis of this particular team but could be applied to any size group.

As might be expected, some individual member's self-ratings differed considerably from peer rating. In some instances, self-ratings were higher than peer ratings. Team Member 2 is a good example of this; she awarded herself ratings of 6.0 and 7.0 on all the variables. The table shows, however, that the other five team members did not share her view of her own performance. The Wilcoxon test showed a significant difference between peer and self-rating for this individual $(\mathrm{p}=.008)$. This analysis suggests that her peers did not see her as an acceptable team member. Additional written comments provided by her peers might help explain whether she was a free rider or social loafer. 
Table 2: Comparisons Of Self-Ratings Of Respective Performances By All Team Members With Ratings Of Performances By Their Peers

\begin{tabular}{|c|c|c|c|c|c|c|}
\hline \multirow[b]{2}{*}{ Factor } & \multicolumn{6}{|c|}{ Group Member } \\
\hline & 1 & 2 & 3 & 4 & 5 & 6 \\
\hline \multicolumn{7}{|c|}{ Attendance at Meeting } \\
\hline Self-Rating & 6.0 & 6.0 & 6.0 & 6.0 & 6.0 & 7.0 \\
\hline Peer-Rating & 5.5 & 3.0 & 3.5 & 5.3 & 7.0 & 7.0 \\
\hline \multicolumn{7}{|c|}{ Shows Team Appreciation } \\
\hline Self-Rating & 6.0 & 6.0 & 7.0 & 6.0 & 6.0 & 7.0 \\
\hline Peer-Rating & 5.3 & 3.0 & 3.3 & 5.3 & 7.0 & 7.0 \\
\hline \multicolumn{7}{|c|}{ High Quality Ideas / Standards } \\
\hline Self-Rating & 5.0 & 6.0 & 5.0 & 6.0 & 6.0 & 5.0 \\
\hline Peer-Rating & 5.0 & 3.0 & 4.8 & 6.0 & 6.0 & 6.3 \\
\hline \multicolumn{7}{|c|}{ Dependable, Trustworthy } \\
\hline Self-Rating & 6.0 & 7.0 & 7.0 & 6.0 & 6.0 & 7.0 \\
\hline Peer-Rating & 5.8 & 1.8 & 4.3 & 5.8 & 6.7 & 6.7 \\
\hline \multicolumn{7}{|c|}{ Promotes Shared Goals } \\
\hline Self-Rating & 6.0 & 7.0 & 5.0 & 7.0 & 6.0 & 5.0 \\
\hline Peer-Rating & 5.8 & 3.6 & 4.8 & 6.3 & 6.7 & 7.0 \\
\hline \multicolumn{7}{|c|}{ Facilitated Goal Achievement } \\
\hline Self-Rating & 6.0 & 7.0 & 7.0 & 6.0 & 5.0 & 6.0 \\
\hline Peer-Rating & 5.5 & 2.5 & 4.8 & 6.3 & 6.3 & 6.7 \\
\hline \multicolumn{7}{|c|}{ Allows Group to Take Responsibility for Tasks } \\
\hline Self-Rating & 5.0 & 6.0 & 6.0 & 5.0 & 6.0 & 5.0 \\
\hline Peer-Rating & 5.3 & 1.8 & 3.5 & 5.5 & 6.0 & 6.0 \\
\hline \multicolumn{7}{|c|}{ Communicates Need for Teamwork / Cooperation } \\
\hline Self-Rating & 6.0 & 7.0 & 7.0 & 7.0 & 5.0 & 7.0 \\
\hline Peer-Rating & 6.8 & 3.3 & 6.0 & 4.5 & 6.3 & 6.7 \\
\hline \multicolumn{7}{|c|}{ Overall Assessment } \\
\hline Self-Rating & 6.0 & 6.0 & 5.0 & 6.0 & 6.0 & 6.0 \\
\hline Peer-Rating & 5.5 & 3.0 & 4.0 & 5.5 & 6.7 & 6.7 \\
\hline
\end{tabular}

In some other instances, team members' self-ratings were lower than the peer ratings. Team Member 5 is an example of this phenomenon. This person consistently rated herself lower than her peers rated her. The Wilcoxon test revealed a significant difference between peer and self-ratings for this individual, also. For whatever reasons, she believed she contributed less to the group than her peers thought she did. She was seen by her peers as a much better performer then she believed herself to be. Written comments accompanying the assessment form suggest that, over time, she also became the unofficial team leader.

For other team members, individual and peer ratings were in agreement on some items and in disagreement on others. This may be seen in the case of Team Member 1, who is a very good example of pattern of slight disagreement that is not significant. This individual's self-ratings were relatively close to his peers' ratings on most of the variables, some being slightly higher and others slightly lower: the Wilcoxon test indicated no significant difference between peer and self-ratings.

The purposes of comparing peer and self-ratings is that, when combined, they allow the instructor better insight than would be obtained by using only one or the other. This comparison also allows instructor assistance if learners complained about inequitable grading. For example, assume that Team Member 2 receives a grade that she believes is unfair and complains to the instructor. Since this individual rated herself higher in all criteria, she may feel that she merited the highest possible grade. As Table 2 shows, her peers did not agree with her. Peer rankings and comments provided by the instructor with additional information to use in determining the equity of the assigned grade. 
For the class from which this typical team was chosen, the instructor interviewed all learners prior to placing them into teams, using the interviews to place learners into various group positions based on their qualifications and interests, rather than on their personal friendships. Another method is to have students apply for team position based upon cover letters and resumes. Both process helped prevent collusion within groups by learners who might otherwise have attempted to control the rating system to their advantage.

\section{COMPOSITE OF TEAM MEMBERS' PERFORMANCES}

Analysis of Table 2 also shows 6 members of the illustrative team who did not contribute equally, at least not in the eyes of their peers. For example, Team Member 2 was seen as the lowest contributor on all eight items and on the overall assessment rating. Team Member 3, while rated higher than Team Member 2, was also seen as a low contributor. Conversely, Team Member 5 and Team Member 6 were perceived by their peers to be high performers in the group. Team Member 1 and Team Member 4 were viewed as acceptable but not outstanding contributors.

Using peer ratings and each member's self-ratings, it is possible for the instructor to assess the relative level of contribution of each of the group's members. Without such input, the instructor may not be aware that some members outperformed others. This information would permit discussions on the basic traits of top entrepreneurial teams including: high-performing teams driven by entrepreneurs, high-performing ventures in relentless pursue of a vision, the value of "people-skills," and emerging organizational structures within high-performing entrepreneurial enterprises.

These analyses clearly show that, based upon the perspectives of those most directly involved in the project, team member performances were not equal throughout the project. The findings suggest that the six members of this team should not receive the same grade for their performance in the team effort. Some are clearly perceived by their peers as deserving better grades than others deserve.

\section{WEIGHING THE PEER RATING CRITERIA}

Some instructors may wish to weigh some items as more or less important than others do. For example, one instructor may see the input contribution and the work quality items (High/Low Quality Ideas and High/Low Quality Standards) as more important than the other items. While another instructor may view the dependability and availability items (Always/Never Attended Meetings, Available/Unavailable When Needed, and Dependable/Undependable) as more important. Still another instructor may prefer to place more emphasis on the peer group equity and interaction items (Facilitated/Hindered Goal Achievement, Promote Shared Goals/Did Not Promote Shared Goals, and Allows Group to Take Responsibility for Tasks/Assumes Personal Responsibility for Team Tasks). Such weightings might affect judgments about individual group member performance. Changing the weightings of the items is a relatively easy undertaking for an instructor who feels some of the items to be more important than others to perform. Two additional survey model are provided as attachments for instructors.

\section{SUMMARY}

Team projects are used in a variety of entrepreneurship and small business management courses because they provide distinctive benefits to both learners and instructors. Indications are that they will continue to because of the benefits. Such benefits, however, are totally dependent upon members of the team and their individual levels of effort and contribution. When some members become social loafers or free riders, a team's effort is often greatly impaired.

It is important to realize that social loafing and free riding are not inevitable in collective team efforts. Research reveals that these phenomena often do not occur when (1) team goals are compelling; (2) the task involved is challenging, appealing, or involving; and (3) individual performances are identified, monitored and rewarded. Many social psychologists believe that identification of individual performance is the key to more effective use of teams in both classrooms and the workplace. Identification of individual team member work and effort, in turn, 
permits more equitable grading of team members based on their individual contributions to the overall team effort. To a large extent, the problem of inequitable contributions can be lessened with the grading system that gives appropriate weight to both individual contributions and team achievement.

This paper has focused on the importance of entrepreneurial teamwork competencies and the use of peer assessment as a methodology for identifying individual performances. The paper has presented assessment instruments that were developed using the criteria of dependability / trustworthiness and appreciation of team members, contribution of effort, standard quality, promotion of shared goals, facilitation of goal achievement. Distribution of team tasks and overall assessment. These criteria were tested using multiple regression analysis. Examples have shown individual performances in a team differ appreciably, suggesting that the single team grade given to all members might not be equitable. This analysis also has discussed approaches to grading individual team members based on their contributions to the overall effort, as assessed by their peers. These instruments are not recommended, however, for use as the sole criterion in grading team performance. Rather, they should be used as part of an overall assessment process that facilitates more effective grading of team in entrepreneurship courses.

\section{REFERENCES}

1. Bird, B. (1989). Entrepreneurial Behavior. Glenview, Illinois: Scott Foresman.

2. Beckman, M. "Collaborative Learning: Preparation for the Workplace and Democracy." College Teaching, 1990, 38(4), 128-133.

3. Brazeal, Deborah V., and Herbert, Theodore T. (1999). "The Genesis of Entrepreneurship." Entrepreneurship: Theory and Practice, Vol. 24, (3), 5-23.

4. Chickering, A.W. and Gamson, Z.F. (eds.), "Applying the Seven Principles for Good Practice in Undergraduate Education." New Directions for Teaching and Learning, No. 47. San Francisco: Jossey-Bass, 1991.

5. Collier, K.G. "Peer-Group Learning in Higher Education: The Development of Higher-Order Skills." Studies in Higher Education, 1980, 5 (1), 55-62.

6. Connery, B.A. (1988). "Group Work and Collaborative Writing." Teaching at Davis, 14(2), 2-4. Publication of the Teaching Resources Center, University of California at Davis.

7. Cooper, J. (1990). "Cooperative Learning and College Teaching: Tips from the Trenches." Teaching Professor, 4 (5), 1-2.

8. Cooper, J., and Associates (1990). "Cooperative Learning and College Instruction.” Long Beach: Institute for Teaching and Learning, California State University.

9. Dollinger, Marc J. (1999). Entrepreneurship: Strategies and Resources, Upper Saddle River, New Jersey: Prentice Hall.

10. Goldman, D., Boyatzis, R., and McKee, Annie (2002). Primal Leadership. Time Warner Publications, New York, NY.

11. Goodsell, A., Maher, M., Tinto, V., and Associates (eds.) (1992). Collaborative Learning: A Sourcebook for Higher Education. University Park: National Center for Postsecondary Teaching and Learning, and Assessment, Pennsylvania State University.

12. Hackbert, P.H. (2000a). "Critical Entrepreneurial Abilities of Undergraduate Entrepreneurship Graduates in the $21^{\text {st }}$ Century." Working Papers 27. Entrepreneurship Center, Institute for Management and International Entrepreneurship at California State University Monterey Bay.

13. Hackbert, P.H. (2000b). "Critical Teamwork Abilities of Undergraduate Entrepreneurship Graduates in the $21^{\text {st }}$ Century." Working Papers 28. Entrepreneurship Center, Institute for ent and International Entrepreneurship at California State University Monterey Bay.

14. Johnson, D.W. and Johnson, R.T. (1989). Cooperation and Competition: Theory and Research. Edina, Minn.: Interaction Books.

15. Johnson, D.W. and Johnson, R.T. and Smith, K.A. (1991). "Cooperative Learning: Increasing College Faculty Instructional Productivity." ASHE-ERIC Higher Education Report No. 4. Washington D.C.: School of Education and Human Development, George Washington University.

16. Justice, D., and Marineau, C. (1988). "Self-assessment: Essential Skills For Adult Learners." In P. Hutchings and A. Wurtzdorff (eds.), Knowing And Doing: Learning Through Experience. San Francisco: Jossey-Bass. 
17. Kamm, J.B., Schuman, J.C., Seeger, J.A. (1990). "Entrepreneurial Teams in New Venture Creation: A Research Agenda." Entrepreneurship: Theory and Practice, Vol. 14, (4), 7-17.

18. Lorge, I. (1958). "A Survey of the Studies Contrasting the Quality of Group Performance and Individual Performance, 1920-1957," Psychological Bulletin, 55: 37-372.

19. Katzenback, J., and Smith, D. (1993). "The Discipline of Teams," Harvard Business Review, March-April, 111-120.

20. Kohn, A. (1986). No Contest: The Case Against Competition. Boston: Houghton Mifflin.

21. McCarthy, A., D. Krueger, D., and Schoenecker, T. (1990). "Changes in Time Allocation Patterns of Entrepreneurs," Entrepreneurship: Theory and Practice, 15, 7-18.

22. McKeachie, W.J. Pintrich, P.R., Lin, Y.-G., and Smith, D.A.F. (1986). "Teaching And Learning in the College Classroom: A Review of the Research Literature." Ann Arbor: National Center for Research to Improve Postsecondary Teaching and Learning, University of Michigan.

23. Michaelson, L., W. Watson and Black, R. (1989). "A Realistic Test of Individual versus Group Consensus Decision Making," Journal of Applied Psychology, 74, 834-839.

24. Pavitt, C., and Curtis, E. (1990). Small Group Discussion, Scottsdale, AZ.: Gorsuch Scarisbrick, 26-29.

25. Prideaux, G., and Ford, J. (1988a). "Management Development: Competencies, Contracts, Teams, And Work-Based Learning." Journal of Management Development, 7 (3), 56-68.

26. Prideaux, G., and Ford, J. (1988b). "Management Development: Competencies, Contracts, Teams, And Work-Based Learning." Journal of Management Development, 7 (3), 13-21.

27. Slavin, R.E. (1980). "Cooperative Learning." Review of Educational Research, 50 (2), 315-342.

28. Slavin, R.E. (1983). "When Does Cooperative Learning Increase Student Achievement?" Psychological Bulletin, 94 (3), 429-445.

29. Tyebjee, T., and Bruno, A. (1984). "A Model of Venture Capitalist Investment Activity," Management Science, 30 (9), 1051-1066.

30. Virany, B., and Tushman, M. (1986). "Top Management Teams and Corporate Success in an Emerging Industry,” Journal of Business Venturing, 1, 261-174.

31. Whitman, N.A. (1988). "Peer Teaching: To Teach Is to Learn Twice." Washington, D.C.: ASHE-ERIC Higher Education Report No. 4. Washington, D.C.: Association for the Study of Higher Education.

\section{PEER- AND SELF-ASSESSMENT INSTRUMENT}

Center for Entrepreneurial Leadership - Sierra Nevada College

\section{Team Member Rating Sheet}

Team Member Being Rated:

I.D. \#

Date:

Instructions:

You are to complete a rating sheet for yourself and all other members of your team. All team members must be rated including yourself. Check the blank location that most accurately reflects your position regarding each of the bipolar statements.

All rating sheets will be kept confidential. No team member will see the rating sheets. The peer- and selfassessment instrument scores will be used by the course instructor(s) to help determine individual team member's contributions to the overall team efforts.

Please rate the team member on the following:

1) Always attended meetings

$\begin{array}{lllllll}7 & 6 & 5 & 4 & 3 & 2 & 1\end{array}$

2) Available when needed
[ ] [ ] [ ] [ ] [ ] [ ] [ ] Never attended meetings

[ ] [ ] [ ] [ ] [ ] [ ] [ ] Unavailable when needed 
3) High quality ideas

4) Dependable

5) High quality work

6) Facilitated goal achievement

7) Did more than fair share

8) Easy to work with

9) Assertive

10) Resolved conflict, tension

11) Uses meeting time efficiently

12) Encourages team thinking

13) Summarizes key points

14) Consensus taking

15) Logical

16) Clear

17) Idealistic

18) Systematic

19) Confident

20) Tactful

21) Considerate of others

22) Accepts responsibilities

23) Tolerates diversity of ideas

24) Honest, trustworthy

25) Overall evaluation (high)
[ ] [ ] [ ] [ ] [ ] [ ] [ ] Low quality ideas

[ ] [ ] [ ] [ ] [ ] [ ] [ ] Undependable

[ ] [ ] [ ] [ ] [ ] [ ] [ ] Low quality work

[ ] [ ] [ ] [ ] [ ] [ ] [ ] Hindered goal achievement

[ ] [ ] [ ] [ ] [ ] [ ] [ ] Did less than fair share

[ ] [ ] [ ] [ ] [ ] [ ] [ ] Difficult to work with

[ ] [ ] [ ] [ ] [ ] [ ] [ ] Withdrawing

[ ] [ ] [ ] [ ] [ ] [ ] [ ] Increased conflict, tension

[ ] [ ] [ ] [ ] [ ] [ ] [ ] Inefficient use of meeting time

[ ] [ ] [ ] [ ] [ ] [ ] [ ] Discourages team thinking

[ ] [ ] [ ] [ ] [ ] [ ] [ ] Lost in the decision making

[ ] [ ] [ ] [ ] [ ] [ ] [ ] Unable to discern consensus

[ ] [ ] [ ] [ ] [ ] [ ] [ ] Illogical

[ ] [ ] [ ] [ ] [ ] [ ] [ ] Unclear

[ ] [ ] [ ] [ ] [ ] [ ] [ ] Unrealistic

[ ] [ ] [ ] [ ] [ ] [ ] [ ] Spontaneous

[ ] [ ] [ ] [ ] [ ] [ ] [ ] Unsure

[ ] [ ] [ ] [ ] [ ] [ ] [ ] Oblivious to others' feelings

[ ] [ ] [ ] [ ] [ ] [ ] [ ] Inconsiderate of others

[ ] [ ] [ ] [ ] [ ] [ ] [ ] Avoids responsibilities

[ ] [ ] [ ] [ ] [ ] [ ] [ ] Close minded to different ideas

[ ] [ ] [ ] [ ] [ ] [ ] [ ] Unethical in practice

[ ] [ ] [ ] [ ] [ ] [ ] [ ] Overall evaluation (low)

If you wish to provide any other information on this team member, please do so on the back of the page.

\section{Periodic Peer Assessment of Entrepreneurial Team Members}

A percentage of the individual course grade can be earned as a part of the E-Team grade received from peers awarded by an individual's teammates on the basis of the value of that person's contribution to the E-Team effort. Five different scores can be awarded: 1, 3, 5, 7, or extra credit. The meaning of each score is explained below. Please read the explanation of each score, and then rate yourself and each of your teammates by circling the appropriate number.

1 Point: This person's presence and participation was counterproductive for the team. Some of the ways in which a person's presence can be counterproductive include the following: (1) failure to perform tasks which meant others had to complete or revise this person's work-tasks; (2) tardiness in completing assignments seriously delayed the team's work, affecting the quality of the team's overall performance; (3) poor interpersonal skills which disrupted the team meetings; (4) lacks ability to clearly express ideas, presents illogical arguments, close mindedness, lack of consideration, or avoids responsibility. Awarding 1 point will reduce this person's project grade to the next lowest letter - e.g., if the E-project earns an " $B$," this person will earn a " $C$."

3 Points: This person fulfilled his/her tasks as assigned, but did only the bare minimum work, and did not respond to the need to produce high quality work products. This person is still developing professional teamwork skills and practices behavior which is inconsistent, unrealistic, undependable, and demoralizing. Awarding 3 points will reduce this person's E-project grade by two steps - e.g., if the E-project earn a “ $B+$," this person will earn a "B-."

5 Points: This person fulfilled his/her assignments and also made some effort to respond to the need to produce high-quality work products. In awarding 5 points, I am acknowledging this person's desire to produce high 
quality products, while recognizing that a more consistent professional effort or knowledge would have produced an even better work product. Awarding 5 points will reduce this person's project grade by one step -e.g., if the project earn a " $B+$," this person earn a "B."

7 Points: This person's contribution showed regard for the team's desire to produce an outstanding - to excellent work product and presentation; what this person did was essential to the success of the team's effort, demonstrates professional behavior. Awarding 7 points ensures that this person will get full credit on the projecte.g., if the project earns an " $A$," this person will earn an " $A$.".

Extra Credit:Awarding an extra credit designation means that this person contributed more than his/her share in terms of amount or quality or results and is an exceptional professional. Awarding extra credit will increase this person's project grade - e.g., if the project earns " $B$," this person earns a " $B+$. ."

Can't Assess: Some reasons for marking "can't assess" are listed below: (1) the work tasks were accepted by the team but because he or she worked independently, I can't judge the contribution of the work; (2) this person worked hard, but I had a disagreement with this person that made it difficult for me to assess him/her objectively. The faculty may inquire for documentation in support of this assessment.

\section{Name:}

\begin{tabular}{|c|c|c|c|c|c|c|}
\hline & 1 & 3 & 5 & 7 & Extra Credit & Can't Assess \\
\hline & 1 & 3 & 5 & 7 & Extra Credit & Can't Assess \\
\hline & 1 & 3 & 5 & 7 & Extra Credit & Can't Assess \\
\hline & 1 & 3 & 5 & 7 & Extra Credit & Can't Assess \\
\hline & 1 & 3 & 5 & 7 & Extra Credit & Can't Assess \\
\hline & 1 & 3 & 5 & 7 & Extra Credit & Can't Assess \\
\hline Yourself & 1 & 3 & 5 & 7 & Extra Credit & Can't Assess \\
\hline
\end{tabular}


Notes 